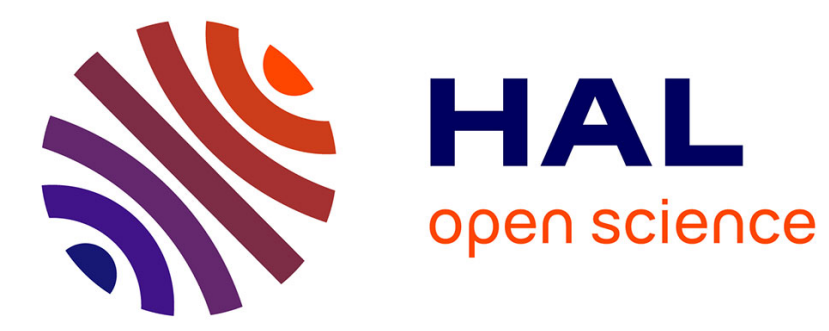

\title{
Constituent particle break-up during hot rolling of AA 5182
}

Nicolas Moulin, Estelle Parra-Denis, Dominique Jeulin, Christophe Ducottet, Annabelle Bigot, Elodie Boller, Éric Maire, Cecile Barat, Helmut Klöcker

\section{- To cite this version:}

Nicolas Moulin, Estelle Parra-Denis, Dominique Jeulin, Christophe Ducottet, Annabelle Bigot, et al.. Constituent particle break-up during hot rolling of AA 5182. Advanced Engineering Materials, 2010, 12 (1-2), pp.20-29. 10.1002/adem.200900241 . hal-00681824

\section{HAL Id: hal-00681824 https://hal.science/hal-00681824}

Submitted on 22 Mar 2012

HAL is a multi-disciplinary open access archive for the deposit and dissemination of scientific research documents, whether they are published or not. The documents may come from teaching and research institutions in France or abroad, or from public or private research centers.
L'archive ouverte pluridisciplinaire HAL, est destinée au dépôt et à la diffusion de documents scientifiques de niveau recherche, publiés ou non, émanant des établissements d'enseignement et de recherche français ou étrangers, des laboratoires publics ou privés. 


\section{Constituent Particle Break-up during Hot Rolling of AA 5182}

Nicolas Moulin ${ }^{(1)}$, Estelle Parra-Denis ${ }^{(2,3)}$, , Dominique Jeulin ${ }^{(3)}$, Christophe Ducottet $^{(2)}$, Elodie Boller $^{(4)}$, Eric Maire ${ }^{(5)}$, Cécile Barat ${ }^{(2)}$, Helmut Klöcker ${ }^{(1)}$

(1) Ecole des Mines de Saint-Etienne, 158 Cours Fauriel, 42000 Saint Etienne, France

(2) Laboratoire Hubert Curien, CNRS UMR 5516, Université de Saint-Étienne, France

(3) Centre de Morphologie Mathématique, Mathématiques et Systèmes, Mines ParisTech, France.

(4) ESRF, 6 rue Jules Horowitz, BP220, 38043 GRENOBLE CEDEX

(5) Materials Science Laboratory (MATEIS) CNRS-UMR 5510. INSA-Lyon, France klocker@emse.fr

Keywords : Al-Mg alloy, constituent particles, 3D metallography, statiscal analysis, morphological characterization, FE-simulations.

\section{ABSTRACT}

Aluminium sheet is currently used for body panels on a number of mass-produced vehicles, in particular for closure panels. AA5xxx alloys always contain coarse intermetallic particles $\left(\mathrm{Al}_{\mathrm{x}}(\mathrm{Fe}, \mathrm{Mn})_{\mathrm{y}} \mathrm{Si}, \mathrm{Mg}_{2} \mathrm{Si}\right)$ after casting, undesirable for the final sheet forming and stamping operations. In the present work intermetallic particle break-up during hot reversible rolling of AA5182 alloy sheets has been analysed.

The sizes and shapes of intermetallic particles in as-cast and industrially hot rolled AA5182 alloys sheets were characterized by 3D X ray tomography observations. The relation between particle break-up and particle morphology was then analysed statiscally and by a micromechanical finite element based model.

The essential outcomes of the statiscal approach may be summarized as follows. The intermetallic particle population may be described by five morphological parameters (three parameters in the principal component space), allowing us to follow the evolution of intermetallic particles during hot rolling. Secondly the comparison of the particle morphology in as cast and industrially rolled sheets leads to the definition of 5 classes. The evolution of each particle class as function of the rolling strain is provided. The statistical analysis shows which particles break-up.

The stresses and strains in inter-metallic particles, embedded in an elasto-viscoplastic aluminium matrix submitted to plane strain compression, were analysed by a finite element (FE) model. A new failure criterion for brittle pre-cracked solids embedded in a soft matrix submitted to large straining was proposed. The essential outcomes of the mechanical approach 
are as follows: a precise description of stress concentration mechanisms in non convex particles, a close description of the parameters controlling particle break-up, and finally a simplified classification of the failure behaviour of inter-metallic particles.

\section{INTRODUCTION}

AA5xxx alloys are used for inner body panels on a number of mass-produced vehicles. AA5182 is the material of choice for complex stampings. After casting and homogenization, the alloy is hot rolled (strain of 3) and cold rolled (additional strain of about 2). It is provided under the form of $1 \mathrm{~mm}$ thick annealed and fully recrystallised ( $\mathrm{O}$ temper) sheets. The last step is the cold forming of the sheets to obtain the final shape by plastic deformation.

Table 1 shows the chemical composition of AA5182. This alloy always contains coarse inter-metallic particles (iron-rich (Fe,Si) $)_{\mathrm{m}} \mathrm{Al}$ and $\mathrm{Mg}_{2} \mathrm{Si}$ ). Figure 1 shows SEMobservations (obtained after selective dissolution of the Al-matrix at the CRV/Alcan Research Centre). In the undeformed sample, particles have a non-convex, branched shape. These large inter-metallic particles $(>1 \mu \mathrm{m})$ are underisable for the final sheet forming operations. The dispersoids $(<1 \mu \mathrm{m})$ do not play a major role on the damage behaviour. In previous work, the break-up of these inter-metallic particles during hot and cold rolling were characterised experimentally $[\mathbf{1 , 2}]$. The particle volume decreases essentially during hot reversible rolling.

In the present work, the particle break-up in industrially hot reversible rolled AA5182 sheet was analysed. In X-ray tomographic observations, $\mathrm{Mg}_{2} \mathrm{Si}$-particles have almost the same grey level as the aluminium matrix. The segmentation method had to be optimized for these alloys. The image acquisition technique and the segmentation algorithm are explained in section 2. A $1 \mathrm{~mm}^{3}$ volume of as cast alloy contains about 26000 complex shaped inter-metallic particles. In section 3, a statistical analysis of particle break-up is presented. This analysis shows that five morphological parameters (three parameters in the principal component space) allow us to describe the evolution of inter-metallic particles during hot rolling. Secondly, the comparison of the particle morphology in as cast and industrially rolled sheets leads to the definition of five classes. The evolution of each particle class as a function of the rolling strain is provided. The statistical analysis shows which particles break-up. The mechanical model in section 4 analyses why the particles break-up. First it is shown that non convex particles are submitted to particular stress concentration mechanisms. Then a new failure criterion for precracked brittle solids embedded in a ductile matrix is proposed. Finally the new failure criterion is applied to a selection of particles of each the 5 classes of the statistical analysis and a new slightly simpler classification is proposed. 


\section{EXPERIMENTAL PROCEEDURE}

\subsection{Experimental set-up}

The sizes and shapes of intermetallic particles in as-cast and industrially homogenised and hot rolled (10\%, 82\% and $123.5 \%$ equivalent strain) AA5182 sheets were characterized by 3D X-ray tomography observations. Samples of dimensions $1 \times 1 \times 10 \mathrm{~mm}^{3}$ were cut at different locations in the sheet (Figure 2a). The volumes analysed by X-ray tomography measure 0.027 $\mathrm{mm}^{3}$. The conditions of acquisition and of processing of 3D images are given in Table 2. Figure $2 \mathbf{b}$ shows an image of the as cast state.

\subsection{D-segmentation}

The studied aluminium alloy contains two types of inter-metallic particles : iron rich $\left((\mathrm{Fe}, \mathrm{Si})_{\mathrm{m}} \mathrm{Al}\right)$, and silicon containing particles $\left(\mathrm{Mg}_{2} \mathrm{Si}\right)$. Figure 3a shows the X-ray microtomographic image of AA5182. The grey levels of iron rich particles are bright. Voids are dark surrounded with a bright halo due to the phase contrast used during the acquisition protocol $\mathrm{Mg}_{2} \mathrm{Si}$ particles have almost the same grey level as the aluminium matrix. $\mathrm{Mg}_{2} \mathrm{Si}$ particles show almost the same grey level as the aluminium matrix and are also surrounded with a bright halo. The segmentation method was thus optimized for these alloys [3]. The segmentation algorithm is divided into three main parts (Figure 3b). In a first step, a Gaussian filter is applied to smooth the image [4,5]. In the second step (multiclass thresholding), each type of particle is thresholded separately from the others with a high and a low threshold. To increase the grey level difference between $\mathrm{Mg}_{2} \mathrm{Si}$ and matrix, a phase contrast is used and the image is saturated in black and white levels, generating a halo artefact in the surrounding area of the particle. The last step consists in a combination of the previous step results in order to extract the halo artefact. The final result is a thin segmentation of each type of particle, as illustrated on Figure 3c. Figure 4 shows 3D images of the inter-metallic particles and the micro-voids in an as cast alloy after segmentation.

\section{STATISTICAL ANALYSIS OF PARTICLE BREAK-UP}

Due to the large number of complex shaped particles $\left(\sim 26000 / \mathrm{mm}^{3}\right)$, a statistical study must be performed leading to a description of shapes with a minimum number of parameters. Table 3 gives the number of observed particles for each rolling stage (deformation).

Most of the 3D shape analysis algorithms in the literature [7,8] apply to simple 3D shapes or star-shaped objects. E. Parra et al. [9] developed a methodology to carry out 3D complex shape analysis using morphological features adapted to inter-metallic particles. The 
results of this work are summarized in section 3.1. To handle the data, the principal component analysis [6] (PCA) is most adequate.

\subsection{Morphological features}

The shape parameters can be divided into four categories: basic measures (volume $\mathrm{V}$ and surface $S$ ), shape indexes (for example the index of sphericity $I_{s}=36 \pi(V / S)^{2}$ ), geodesic measures (based on the geodesic distance [10]), and mass distribution parameters. E. Parra et al. [9] introduced the geodesic elongation index ( $\mathrm{IGg}$ ), as an extension to 3D of the well known geodesic stretching index in 2D [10]. It characterizes the object elongation and is defined as:

$$
\mathrm{IG}_{\mathrm{g}}=\frac{\pi \mathrm{L}_{\mathrm{g}}^{3}}{6 \mathrm{~V}},
$$

where $\mathrm{L}_{\mathrm{g}}$ is the geodesic length, i.e. the maximum length of a connected path within the shape.

In the present work a uniform density inside the particles is assumed, thus the moments of inertia (eigenvalues of the inertia matrix) characterize the particle shape [3]. If $I_{1}$, $\mathrm{I}_{2}, \mathrm{I}_{3}$ denote the moments of inertia, the normalized moments $\lambda_{1}, \lambda_{2}, \lambda_{3}$ are defined as: $\lambda_{\mathrm{i}}=\mathrm{I}_{\mathrm{i}} /\left(\mathrm{I}_{1}+\mathrm{I}_{2}+\mathrm{I}_{3}\right), \mathrm{i}=1,2,3$. Their sum is equal to 1 and they are ordered: $\lambda_{1} \geq \lambda_{2} \geq \lambda_{3}$. From those equations and the definition of inertia moments, the two following inequalities can be deduced [9] :

$$
\begin{aligned}
& \lambda_{\mathrm{i}} \leq 0.5 \forall \mathrm{i} \in(1,2,3) \\
& \lambda_{2} \geq 0.5\left(1-\lambda_{1}\right)
\end{aligned}
$$

\subsection{Principal Components Analysis and particle classification}

\section{a. Principal component analysis}

Measurements of the previous morphological parameters were made on 3500 intermetallic particles for a $10 \%$ deformed aluminium alloy. Linearly correlated parameters were removed before applying PCA in order to avoid the redundancy between the measurements of the particles. Finally, the considered parameters are: the volume, the sphericity index, the geodesic elongation index and two normalized eigenvalues of the inertia matrix $\left(\lambda_{1}, \lambda_{2}\right)$. The data matrix is therefore composed of 3500 particles and 5 parameters describing each particle. For the present study, we only keep the first three axes since they represent $87.8 \%$ of the variability [9].

The relation between variables in the Principal Component space $\left(\mathrm{PC}_{\mathrm{i}}\right)$ and the morphological parameters are given in Table 4 for rolling strains of 10\%, 19\%, 82\% and $123 \%$.

Figure 5 shows the variation of the morphological parameters with the first 3 variable in the 
principal component space. $\mathrm{IGg}$ andV increase with $\mathrm{PC}_{1}$, whereas $\mathrm{I}_{\mathrm{s}}$ decreases if $\mathrm{PC}_{1}$ increases. Effectively, $\mathrm{PC}_{1}$ characterizes elongation changes. The more elongated an object is $\left(\mathrm{I}_{\mathrm{S}} \neq 1\right)$, the larger it is. Axis 3 suggests that the larger a particle, the smaller $\lambda_{1}$ and $\lambda_{2}$, which means that large particles tend to have a spherical mass distribution $\left(\lambda_{1}=\lambda_{2}=\lambda_{3}\right)$, while small ones tend to have a flat or cylindrical mass distribution. Axis 2 allows us to distinguish objects with a flat mass distribution from ones having a needle mass distribution. Finally, a hierarchical ascendant classification of the particles in the PCA space leads to 5 classes of particles. The following classes (types) of particles were defined (Figure 6):

1. type 1: small, compact particles with a spherical mass distribution,

2. type 2: complex with large volume particles,

3. type 3: elongated in one $3 \mathrm{D}$ direction particles,

4. type 4 : cigar shaped particles,

5. $\quad$ type 5: complex particles with large plane parts.

Figure 7 shows the numerical fraction of the 5 particle types at different hot rolling stages. The population of rather convex particles (type 1 and 4) increases, while the proportion of non convex particles (types 2, 3, 5) decreases during hot rolling. Particular stress concentration seems thus to operate in non convex shaped particles. In the next section, a mechanical analysis of the break-up of non convex shaped particles embedded in an elastoviscoplastic matrix is presented.

\section{MECHANICAL ANALYSIS OF PARTICLE BREAK-UP}

\subsection{Parameter describing particle ability for break-up}

The brittle inter-metallic particles fail in mode I. Figure 1b shows a SEM-observation of a typical iron-rich particle in the as cast alloy after solidification. Moulin et al. [12] proposed a new failure criterion based on the comparison between an active volume $\mathrm{V}_{\mathrm{a}}$ and a critical volume $\mathrm{V}_{\mathrm{c}}$. In the active volume $\mathrm{V}_{\mathrm{a}}$, the maximal principal stress $\sigma_{\mathrm{pmax}}$ is larger than a threshold stress $\sigma_{\text {th }}$. Failure may occur, if the active volume $\mathrm{V}_{\mathrm{a}}$ is larger than the critical volume $\mathrm{V}_{\mathrm{c}}$.

$$
\left\{\begin{array}{l}
\sigma_{\mathrm{pmax}} \geq \sigma_{\mathrm{th}} \quad \forall \overrightarrow{\mathrm{x}} \in \mathrm{V}_{\mathrm{a}}\left(\mathrm{E}_{\infty}, \sigma_{\mathrm{th}}\right) \\
\mathrm{V}_{\mathrm{a}}\left(\mathrm{E}_{\infty}, \sigma_{\mathrm{th}}\right) \geq \mathrm{V}_{\mathrm{c}}\left(\mathrm{K}_{1 \mathrm{c}}, \sigma_{\mathrm{th}}\right)=\left(\frac{\alpha}{\pi}\right)^{3}\left(\frac{\mathrm{K}_{1 \mathrm{C}}}{\sigma_{\mathrm{th}}}\right)^{6}
\end{array}\right.
$$

$\alpha$ is a numerical factor taking into account possible crack interaction, blunting,....

The active volume $\mathrm{V}_{\mathrm{a}}$ describes the ability of a particle to break-up for a given remote loading. $V_{a}$ depends on the value of the threshold stress $\sigma_{t h} \square$ and $\square$ the remote loading $E_{\infty}$ (for example the remote equivalent strain) and the particle shape and orientation. Vc takes into account particle toughness. 
The stress and strain concentrations in ellipsoidal inclusions or second phase particles was analysed in many publications [13-31 $]^{\mathbf{1}}$. In non convex particles, large stress and strain gradients are observed. Moulin et al. [12] analyzed the 2D deformation mechanism of several single non convex elastic particles embedded in a square elastoviscoplastic solid submitted to plane strain deformation. Figure 8a shows typical velocity fields around an L-shaped particle estimated by a Finite Elements (FE) computation. Far from the particle the velocity field corresponds to the homogeneous boundary condition. The velocity is non zero between the particle branches and close to the particle. Though exhibiting a large modulus, the inter-metallic particles are strained during the overall deformation. The velocity field inside the particle is illustrated in Figure 8b. The particle is submitted to pure bending. Figure 9a shows the active zones $\left(\sigma_{\mathrm{pm}}>\sigma_{\mathrm{th}}\right)$ in the L-shaped particle for a threshold stress $\sigma_{\mathrm{th}}=800 \mathrm{MPa}$ and a remote strain of $20 \%$. The active elements (satisfying $\sigma_{\mathrm{pm}}>\sigma_{\mathrm{th}}=800 \mathrm{MPa}$ ) constitute three independent zones $\left(z_{1}\right.$ to $\left.z_{3}\right)$. Figures $9 b$, $\mathbf{c}$ show the volumes of zones $z_{1}, z_{2}$ and $z_{3}$ as a function of the threshold stress and the remote strain. Zones $z_{2}$ and $z_{3}$ will never lead to failure, because their volume is always smaller than $\mathrm{V}_{\mathrm{c}}$, while zone $\mathrm{z}_{1}$ may lead to particle failure. In real inter-metallic particles, several tens of stress raisers have to be considered. A special algorithm assembling the active elements (where $\sigma_{\mathrm{pm}}>\sigma_{\mathrm{th}}$ for at least one Gauss point, implemented in the FE software, was used to analyze the active volume in real intermetallic particles.

\section{2.}

The volume based failure criterion was been applied to selection of real inter-metallic particles. A cubic cell of initial length $L_{x}=L_{y}=L_{z}$ (Figure 10) containing a complex shaped particle was submitted to plane strain compression corresponding to rolling conditions:

$$
\mathrm{E}_{\mathrm{RD}, \mathrm{RD}}^{\infty}=\ln \left(\frac{\mathrm{L}_{\mathrm{x}}}{\mathrm{L}_{\mathrm{x}}^{0}}\right), \mathrm{E}_{\mathrm{ND}, \mathrm{ND}}^{\infty}=\ln \left(\frac{\mathrm{L}_{\mathrm{y}}}{\mathrm{L}_{\mathrm{y}}^{0}}\right), \mathrm{E}_{\mathrm{TD}, \mathrm{TD}}^{\infty}=0
$$

The particle volume fraction was set equal to $0.2 \%$. Perfect bonding at the matrix-particle interfaces was assumed. The choice of particular real particles was based on the morphological analysis. Seven particles of each type were randomly been chosen. For each particle, three possible orientations relative to the rolling axes were considered (Figure 10). Each type is thus represented by 21 combinations of particle shapes and orientations relative to the rolling axes.

The matrix material is described as an isotropically hardening elastic-viscoplastic solid. The matrix flow stress $\sigma_{M}$ is given by the following empirical relation:

\footnotetext{
${ }^{1}$ Helmut et Nicolas: est-il possible de limiter le nombre de références sur ce thème aux plus pertinentes ?
} 


$$
\sigma_{M}=g(\bar{\varepsilon})\left(\frac{\dot{\bar{\varepsilon}}}{\dot{\varepsilon}_{0}}\right), g(\bar{\varepsilon})=\sigma_{0}\left(1+\frac{\bar{\varepsilon}}{\varepsilon_{0}}\right)^{n}, \varepsilon_{0}=\frac{\sigma_{0}}{E}
$$

Here, $\bar{\varepsilon}=\int \dot{\bar{\varepsilon}} d t$ and $g(\bar{\varepsilon})$ represents the effective stress vs. effective strain response in a tension test carried out at a strain rate such that $\dot{\bar{\varepsilon}}=\dot{\varepsilon}_{0}$. The initial flow stress $\sigma_{0}(138 \mathrm{MPa})$, the strain rate sensitivity $m(0.055)$ and the strain hardening parameter $n(0.01)$ of the AA5xxx alloy were determined experimentally [2] by hot channel die compression. The ratio between the initial yield stress $\sigma_{0}$ and Young's modulus $E$ was kept constant throughout this paper ( $\left.E=500 \sigma_{0}\right)$, corresponding to most material behaviours at working temperature.

The particle surface was meshed with the marching-cube algorithm [32], for 3D FE calculations. The particle and cell volume were meshed with linear tetrahedrons. The mesh was generated with AMIRA software [33]. The details of the finite element mesh are given in [12].

Figure 11 shows the active volume of the different particles as a function of the threshold stress. The three different orientations of a same particle are represented in the same colour. The distance between curves of the same colour indicates if the particle behaviour is orientation dependent or not. The active volume of type 1 particles is rather orientation independent and decreases extremely rapidly if the threshold stress is increased. The active volume in elongated type 4 particles depends strongly on the orientation. The active volume of the small compact particles (type 1 and type 4) is small for all threshold values. The active volume in the very large type 2 and type 5 particles is large for each threshold stress and rather orientation independent. Type 3 particles lead to intermediate active volumes with orientation dependence. Type 4 particles are most orientation dependent. Type 1, 2 and 5 particles depend slightly on the orientation and type 3 particles are almost orientation independent. In the light of these results a new classification was proposed:

Class $\mathrm{A}^{\prime}=$ type $1+$ type 4

Class B'= type 2 and type 5

Class $C^{\prime}=$ type 3 .

Figure 12 shows the new particle distribution at different rolling stages. Particles in class A' never break-up. Class B' particles break-up at the early hot rolling stages (between 10 and $82 \%$ ) and class C' (type 3) particles break-up at the end of the hot rolling. At the end of the hot rolling, class B' particles represent still a significant fraction of the total number of particles. Type 3 particles may exhibit a large failure strain, but all these particles break. The significant number of particles in class B' after a $123 \%$ rolling strain corresponds thus probably to type 5 particles. 


\section{Conclusions and outlook}

The break-up of inter-metallic iron-rich particles $\left(\sim 26000 / \mathrm{mm}^{3}\right)$ in an aluminium alloy during industrial hot rolling was analysed. A new segmentation algorithm with multiclass thresholding was developed. The particle break-up was analysed stastically and by a mechanical FEA based model. The essential outcomes of the statiscal analysis based on the particle morphology at different hot rolling stages are as follows:

- The particle population may be described by 5 morphological parameters (3 in pricincipal component space): the volume, the sphericity index, the geodesic elongation index and two normalized eigenvalues of the inertia matrix $\left(\lambda_{1}, \lambda_{2}\right)$.

○

The particle population may be dived in 5 types :

1. type 1: small, compact particles with a spherical mass distribution,

2. type 2: complex with large volume particles,

3. type 3 : elongated in one $3 \mathrm{D}$ direction particles,

4. type 4 : cigar shaped particles,

5. type 5: complex particles with large plane parts.

The mechanical analysis of particle break-up is based on the 5 particle types defined by the statiscal analysis and a new failure criterion based on the comparison between an active and critical volume. The essential outcomes of the mechanical analysis may be summarized as follows:

- Stress concentrations in non convex particles are :

- $\quad$ bending of these particle branches;

- $\quad$ very large compared to stress concentrations in convex particles;

- almost independent of the matrix particle interface behaviour.

- A new failure criterion based on the comparison between an active and a critical volume.

- The active volume allows characterises the influence of particle shape, hardness and orientation on the stress concentration.

- $\quad$ The critical volume characterises the influence of particle toughness.

- Classification of real inter-metallic particles.

- $\quad$ The 5 classes proposed by statistical analysis give a close description of particle break-up

- This classification was refined by the mechanical analysis. The particles may be divided into 3 classes. In the future, a mechanical analysis of a large number of particles (several thousands of each type) would certainly allow a more precise classification. In each zone, a Weibull analysis could be applied to determine a failure probability.

The present work covers the experimental observation, the statistical and mechanical analysis of the break-up of non convex shaped particles. The statiscal analysis allowed a guinen choice of the particles to be analysed by finite element simulation. Present work proves the feasibility of a particle classification and the major interest in combining a statiscal analysis of complex shaped solids submitted to complex loading paths followed by a subsequent Finite Element based mechanical modelling. 
The combination of a statistical and mechanical approach allows to analyse a large number of computer generated microstructures (solidification microstructure or mixture of two solids). Alloy weight reduction is one most challenging objective for the next future in applied material science. One possible solution for high performance alloys seems to be the mixture of hard second phase particles and a soft matrix. From our micromechanical approach, it appears that the alloys could be optimised for a particular loading history.

Acknowledgments ${ }^{2}$

References $^{3}$

[1] E. Maire, J.C. Grenier, D. Daniel, A. Baldacci, Klöcker and A. Bigot, (2006), Scripta Materialia 55, 123-126, Quantitative 3D characterization of intermetallic phases in anAl-Mg industrial alloy by $\mathrm{X}$-ray microtomography.

[2] A. Baldacci, A. Bigot, H. Klöcker, J. H. Driver, (2003) Constituent Particle break-up during hot rolling of AA 5182, TMS, San Diego, USA, Marsh 2-6.

[3] E. Parra-Denis, Ch. Ducottet, D. Jeulin, (2005), 3D image analysis of intermetallic inclusions, $9^{\text {th }}$ European congress on Stereology and Image Analysis and $7^{\text {th }}$ STERMAT international Conference on Stereology an Image Analysis in Materials science, Zakopane Poland

[4] Klette R. and Zamperoni P. (1996). Handbook of Image processing operators. Wiley ch 6.

[5] Cocquerez J. P., Philipp S. (1995). Analyse d'images : filtrage et segmentation. Masson ch4.

[6] Greenacre M. J. Theory and applications of correspondence analysis. London: Academic Press; 1984.

[7] Delarue A., Jeulin D., (2003), Image Anal Stereol; 22,153-161. 3D morphological analysis of composite materials with aggregates of spherical inclusions.

[8] Holboth A., Pedersen J., Vedel Jensen E., (2002), J Math Imaging Vis;17,131-7, A deformable template model, with special reference to elliptical models.

[9] Parra Denis E., Barat C., Jeulin D., Ducottet C., (2008), Materials Characterization 59, 338- 343, 3D complex shape characterization by statistical analysis: Application to aluminium alloys.

[10] Lantuejoul Ch., Maisonneuve F. Geodesic methods in quantitative image analysis. Pattern Recogn 1984;17:177.

$[11]^{4} \quad$ Crofton. On the theory of local probability. Phiols Trans $R$ Soc Lond, 1868;158:181199.

$[12]^{5} \quad$ Moulin N., Jeulin D., Klöcker H., (2009), Stress concentrations in non-convex elastic particles embedded in a ductile matrix

[13] Goodier J. N. (1933); J. Appl. Mech., 55, 39-44, Concentration of stress around spherical and cylindrical inclusions and flaws.

[14] Eshelby J. D., (1957), Proc. R. Soc. Lond., A241, 376-396. The determination of the elastic field of an ellipsoidal inclusion and related problems.

[15] Hill R. , (1964), J. Mech. Phys. Solids, 12, 199-212. Theory of mechanical properties of fibre-strengthened materials.

\footnotetext{
${ }^{2}$ Helmut : il me semble qu'il y a des personnes à remercier : A. Bigot (Alcan), collègues de l'ESRF ?

${ }^{3}$ Merci d'homogénéiser les références : mettre partout les initiales des prénoms avant ou après le nom...

${ }_{5}^{4}$ Je ne pense pas que cette référence soit utile ici (pas de rapport avec la distance géodésique...).

${ }^{5}$ Nicolas : à compléter.
} 
[16] Hill R., (1965a), J. Mech. Phys. Solids, 13, 189-198. Theory of mechanical properties of fibre-strengthened materials :II. Self-consistent model.

[17] Hill R., (1965b ), J. Mech. Phys. Solids, 13, 213-222. A self-consistent mechanics of composite materials.

[18] Bhargava R. D., Radhakrishna H. C., (1964), J. Phy. society of Japan, 19, 396-405. Elliptic inclusion in orthotropic medium.

[19] Walpole L. J., (1966a), J. Mech. Phys. Solids, 14, 151-162. On bounds for the overall elastic moduli of inhomogeneous systems - I.

[20] Walpole L. J., (1966b), J. Mech. Phys. Solids, 14, 289-301. On bounds for the overall elastic moduli of inhomogeneous systems - II.

[21] Christensen R. M. Lo K. H., (1979), J. Mech. Phys. Solids, 27, 315-330. Solution for effective shear properties in three phases sphere and cylinder models.

[22] Berveiller M., Zaoui A., (1979), J. Mech. Phys. Solids, 26, 325-344. An extension of the self-consistent scheme to plastically-flowing polycrystals.

[23] Gilormini P., Montheillet F. ,(1986), J. Mech. Phys. Solids, 34, 97-123. Deformation of an inclusion in a viscous matrix and induced stress concentration.

[24] Bhattacharyya A., Weng G. J., (1994), Int. Journal of Plasticity, 10, 553-578. Plasticity of isotropic composites with randomly oriented and packeted inclusions.

[25] T. Christman, A. Needleman, S. Suresh, (1989), Acta Metallurgica 37 (11), 30293050. An Experimental and Numerical Study of Deformation in Metal-Ceramic Composites.

[26] G. Bao, J. W. Hutchinson, R. M. McMeeking, (1991), Acta Metallurgica and Materialia, 39(8), 1871-1882. Particle reinforcement of ductile matrices against plastic flow and creep.

[27] J. Llorca, A. Needleman, S. Suresh, (1991), Acta Metallurgica and Materialia, 39 (10), 2317-2335. An analysis of the effects of matrix void growth on deformation and ductility in metal-ceramic composites.

[28] D. F. Watt, X. Q. Xu, D. J. Lloyd, (1996), Acta Materialia 44 (2), 789-799. Effects of particle morphology and spacing on the strain fields in a plastically deforming matrix,.

[29] J. Llorca, C. Gonzalez, (1998), Journal of the Mechanics and Physics of Solids, 46 (1) 1-5. Microstructural factors controlling the strength and ductility of particle-reinforced metal-matrix composites.

[30] S. Qin, C. Chen, G. Zhang, W. Wang, Z. Wang, (1999), Materials Science and Engineering, A 272 (2), 363-370. The effect of particle shape on ductility of SiCp reinforced $6061 \mathrm{Al}$ matrix composites.

[31] C. Y. Chen, C. G. Chao,(2000), Metallurgical and Materials Transactions, 31A, 2351-2359, Effect of Particle-Size Distribution on the Properties of High Volume Fraction SiCp-Al based Composites.

[32] W.E. Lorensen, H.E. Cline, (1987), SIGGRAPH '87: Proceedings of the $14^{\text {th }}$ annual conference on Computer graphics and interactive techniques, 163-169, New York. USA Marching cubes: A high resolution 3D surface construction algorithm.

[33] AMIRA: Adavanced 3D visualisation and volume modelling, (1999), http://www.amiravis.com.

Légende de la figure 2: b) example of a non segmented

Légende de la figure 5: The morphological parameters were normalised

Table 4: $10 \% \mathrm{~V}-\mathrm{V} 1$ et non -0.66 
Table 3: Précisé qu'il s'agit de iron rich particles. On ne donne pas ici le nombre de particules intermétalliques global. 